Article

\title{
Collaborative Health Impact Assessment and Policy Development to Improve Air Quality in West Yorkshire-A Case Study and Critical Reflection
}

\author{
Yannish Naik ${ }^{1}$, Sally Jones ${ }^{2}$, Helen Christmas ${ }^{3}$, Peter Roderick ${ }^{3}$, Duncan Cooper ${ }^{4}$, \\ Kevin McGready ${ }^{5}$ and Mike Gent ${ }^{6, *}$ \\ 1 Leeds Teaching Hospitals NHS Trust, Leeds LS1 3EX, UK; yannishnaik@nhs.net \\ 2 City of Bradford Metropolitan District Council, Bradford BD1 1HX, UK; sally.jones@bradford.gov.uk \\ 3 Leeds Teaching Hospitals NHS Trust and Public Health England, Yorkshire and the Humber, \\ Leeds LS1 4PL, UK; helen.christmas@nhs.net (H.C.); peter.roderick@nhs.net (P.R.) \\ 4 Wakefield Council, Wakefield WF1 2EB, UK; duncancooper@wakefield.gov.uk \\ 5 Leeds City Council, Leeds LS1 1UR, UK; kevin.mcgready@leeds.gov.uk \\ 6 Public Health England Yorkshire and the Humber, Leeds LS1 4PL, UK \\ * Correspondence: mike.gent@phe.gov.uk; Tel.: +44-113-386-0300
}

Academic Editors: Sotiris Vardoulakis, Jennifer Salmond and Clive Sabel

Received: 26 June 2017; Accepted: 2 August 2017; Published: 10 August 2017

\begin{abstract}
Air pollution is increasingly recognised as a significant problem for cities, with wide ranging impacts on health and quality of life. Combined knowledge of the legal context and health impacts led to air pollution becoming a priority in West Yorkshire. A health impact assessment methodology was used to explore the impacts of low emissions zones, demonstrating significant gains from the implementation of such a measure. This fed in to the collaborative development of the West Yorkshire Low Emissions Strategy (WYLES), resulting in policy changes and an incorporation of health and wellbeing concerns into transport and infrastructure planning, amongst other successes. This case study describes the collaborative approach taken to tackle air pollution locally and summarises key outputs and outcomes of work to date, before providing a critical reflection on what can be learnt from the West Yorkshire experience. This paper will thus interest advocates and stakeholders who are facing similar challenges. Key lessons revolve around broad stakeholder engagement and developing shared ambition. We finally discuss air pollution as a wicked problem, applying the lens of transitions management, a multidisciplinary systems change theory and discuss the local experience in relation to the literature on collaborative public management.
\end{abstract}

Keywords: air pollution; transitions management; collaboration

\section{Introduction}

Air pollution is increasingly recognised as a significant problem for cities, with wide ranging impacts on health and quality of life. Recent work has estimated that air pollution causes approximately 40,000 deaths a year in the UK [1]. The health impacts are also wide ranging and include respiratory disease, cancer, low birth weight and neurodevelopmental issues. The European Union (EU) Air Quality Directive set in place a requirement for countries to assess air quality and limit the levels of certain key pollutants including Nitrogen Dioxide $\left(\mathrm{NO}_{2}\right)$ and particulate matter $\left(\mathrm{PM}_{10}\right.$ and $\left.\mathrm{PM}_{2.5}\right)$ [2]. However, there remains a lack of clarity on how to best deliver improvements in air quality.

Combined knowledge of the legal context and health impacts led to air pollution becoming a priority in West Yorkshire, a region in the North of England. It consists of a population of 2,281,700 (2015 mid-year estimate) living in a mixture of urban and rural areas, within five local authorities [3]. Studies have estimated that 992 deaths a year in West Yorkshire are attributable to fine particulate air 
pollution, and the region has higher rates of hospital admissions for Asthma, COPD and Myocardial infarction than the England average (Table 1) [4]. The primary concern in West Yorkshire is levels of $\mathrm{NO}_{2}$, with some urban areas experiencing some of the highest levels of $\mathrm{NO}_{2}$ concentrations in the UK. The single biggest cause of air pollution in West Yorkshire is road traffic, with industrial and domestic and commercial emissions also adding to background levels magnifying the impact of transport.

Table 1. West Yorkshire Hospital Admissions for Asthma, COPD and Myocardial Infarction, 2012-2013 (Source: WYLES [5]).

\begin{tabular}{cccc}
\hline $\begin{array}{c}\text { Cause of Admission to } \\
\text { Hospital 2012-2013 }\end{array}$ & \multicolumn{2}{c}{ Admissions per 1000 Population } & \multirow{2}{*}{$\begin{array}{c}\text { Additional Admissions in West } \\
\text { Yorkshire Compared to England * }\end{array}$} \\
\cline { 2 - 3 } & West Yorkshire & England & 678 \\
Asthma & 1.39 & 1.09 & 1245 \\
COPD & 2.63 & 2.07 & 463 \\
\hline Myocardial Infarction & 1.39 & 1.18 & \\
\hline
\end{tabular}

* Additional admissions are observed admissions within West Yorkshire minus admissions if the England admission rate was applied to the West Yorkshire population (i.e., the benefit of lower admission rates).

In West Yorkshire, collaboration and multi-stakeholder involvement have led to the development of the West Yorkshire Low Emissions Strategy [5], resulting in policy changes, sustainability initiatives and an incorporation of health and wellbeing concerns into transport and infrastructure planning, amongst other successes. This paper will describe the collaborative approach taken to tackle air pollution locally and summarise key outputs and outcomes of work to date, before providing a critical reflection on what can be learnt from the West Yorkshire experience.

\section{Methods}

\subsection{Evidence Base Development}

We present this health impact assessment (HIA) as an example of work carried out between public health departments to inform policy. In 2014, a collaborative HIA was carried out involving Public Health England (PHE) which is the national governmental public health agency and two West Yorkshire local authorities as part of a Low Emission Zone (LEZ) feasibility study [4]. HIA methodology is widely recognized in the field of public health and is often used to proactively assess the potential positive and negative health implications of policies or developments for communities.

To determine the populations most affected by projected changes in emissions and the estimated health impact an analytical model was developed. The model used source apportionment traffic data already utilised within the LEZ feasibility study representing fleet weighted traffic emissions for each road link in Leeds and Bradford [6]. This was combined with demographic data from the Office for National Statistics to describe the population and areas most affected by pollutants, together with small area health data and research evidence about the health effects of pollutants. From this, the health impact of four future emission scenarios could be calculated, representing realistic LEZ options as well as aspirational targets of the group:

1. Scenario 1: 2016 emissions given pre Euro 4 Buses and HGVs upgraded to Euro 6.

2. Scenario 2: 2021 emissions given all Euro 5 buses are upgraded to Euro 6 .

3. Scenario 3: 2021 emissions assuming that the ratio of petrol to diesel engines for cars and car based vans was the same as it was in the year 2000 (which is $80 \%$ petrol).

4. Scenario 4: 2021 emissions given a 10\% reduction in car and small vehicle journeys.

A literature search was conducted of systematic reviews and meta-analysis where the health effects of $\mathrm{PM}_{2.5}$ or $\mathrm{NOx} / \mathrm{NO}_{2}$ was quantified and generalisable to predominantly urban populations in developed nations. Robust evidence was found for the long term effects of $\mathrm{PM}_{2.5}$ on mortality (all-cause, cardiovascular and respiratory) [7,8], coronary events (hospital admissions plus deaths) [9], 
birth outcomes [10], and suggestive of the long term effects of $\mathrm{NO}_{2}$ on the development of asthma and wheezing [11].

Estimated reduction in health events per year (for the four scenarios) were then calculated from Lower Layer Super Output Area (LSOA) level health data (a commonly used geography in the UK), estimated reductions in emissions, and attributable fractions calculated from the literature search for each LSOA.

All deaths: [deaths per year $] \times\left[\mathrm{PM}_{2.5}\right.$ reduction $\left./ 10 \mu \mathrm{g} / \mathrm{m}^{3}\right] \times[\mathrm{OR}-1 / \mathrm{OR}]$

Cardiopulmonary deaths: [cardiovascular deaths per year] $\times\left[P M_{2.5}\right.$ reduction $\left./ 10 \mu \mathrm{g} / \mathrm{m}^{3}\right] \times[O R-1 / O R]$ Low birth weight due to $\mathrm{NO}_{2}$ : [births $\times$ district Low birth Weight] $\times$ [population weighted $\mathrm{NOx}$ reduction $\left./ 10 \mu \mathrm{g} / \mathrm{m}^{3}\right] \times[\mathrm{OR}-1 / \mathrm{OR}] \times\left[\mathrm{NO}_{2} / \mathrm{NOx}\right.$ ratio of $\left.50 \%\right]$

Asthma development in Leeds due to NOx refers to reduction in lifetime prevalence at age 18 rather than annual events as per the estimates above.

[population 0-19 years $\times$ LSOA prevalence] $\times$ [population weighted NOx reduction $/ 18 \mu \mathrm{g} / \mathrm{m}^{3}$ ] $\times$ $[\mathrm{OR}-1 / \mathrm{OR}] \times\left[\mathrm{NO}_{2} / \mathrm{NO} x\right.$ ratio of $\left.50 \%\right]$

(NB: $\mathrm{OR}$ is the odds ratio; $\mathrm{NO}_{2} / \mathrm{NOx}$ ratio of $50 \%$ estimated after conversations with local stakeholders and based on local monitoring)

Reductions in LSOA health events were summed to calculate district totals and mapped by LSOA. These figures provide estimated approximations of the number of deaths or health events avoided as a result of falling pollution levels.

\subsection{Strategy Development}

Local authorities across West Yorkshire worked together to produce the WYLES [5] in collaboration with Public Health England, the Highways Authority and the West Yorkshire Combined Authority (WYCA) which is a collaborative organization working with local authorities. The strategy links closely with the Leeds City Region Strategic Economic Plan [12] and the West Yorkshire Transport Strategy which is currently in development [13] to ensure cross-sector linkage and commitment.

\subsection{Collaboration}

The collaborative strategy was developed through the WYLES project board including representatives from each local authority, a project manager, a technical advisor, transport representatives and a health representative from Public Health England. This board reported to elected members and other relevant bodies such as Health and Wellbeing Boards and the Transport Committee at WYCA. Each member of the board was responsible for a specific work stream with each work stream being supported by local authorities. A number of collaborations were developed with health and academic organisations, including the Bradford Institute for Health Research (BIHR) and the NHS Improvement Academy. Public Health England acted as a link with wider policy development and provided project capacity. An academic steering group of national experts for input was convened, and peer review and partnership links were also developed with IS Global, an international epidemiological environmental research organisation.

\subsection{Engagement and Awareness Raising}

A broad engagement initiative was carried out as an integral part of the strategy development, including a full public consultation. Infographics were placed as street installations to raise public awareness of air quality-for example an infographic was displayed on air quality stations. Local authority officers worked with local doctors to develop an air quality campaign and petition to raise awareness in the local medical profession [14]. Born in Bradford conducted their own engagement initiatives to disseminate the results of their air quality research. The National Centre for Atmospheric 
Science also conducted roadshows in the region to raise awareness of air pollution and seek input from interested people.

\section{Results}

\subsection{Low Emission Zone Scenario Modelling}

This modelling was able to estimate that an estimated 350 deaths per year in Leeds and 222 deaths per year in Bradford were attributable to particulate air pollution. All four low emission zone scenarios resulted in estimated improvements in air quality across urban areas of Leeds and Bradford, and reductions in mortality were predicted with an estimated range of between 15 and 19 total deaths per year in Leeds and Bradford combined due to lower $\mathrm{PM}_{2.5}$ levels (Table 2). However, a larger group of people would experience health benefits, with an estimated a fall in premature births (3-4), low birth weight (19-45), childhood asthma (254-596) and cardio-pulmonary deaths (8-11) (Table 2).

Table 2. Estimated annual reduction in all deaths, cardiopulmonary deaths and adverse birth outcomes given various LEZ scenarios (Leeds and Bradford combined).

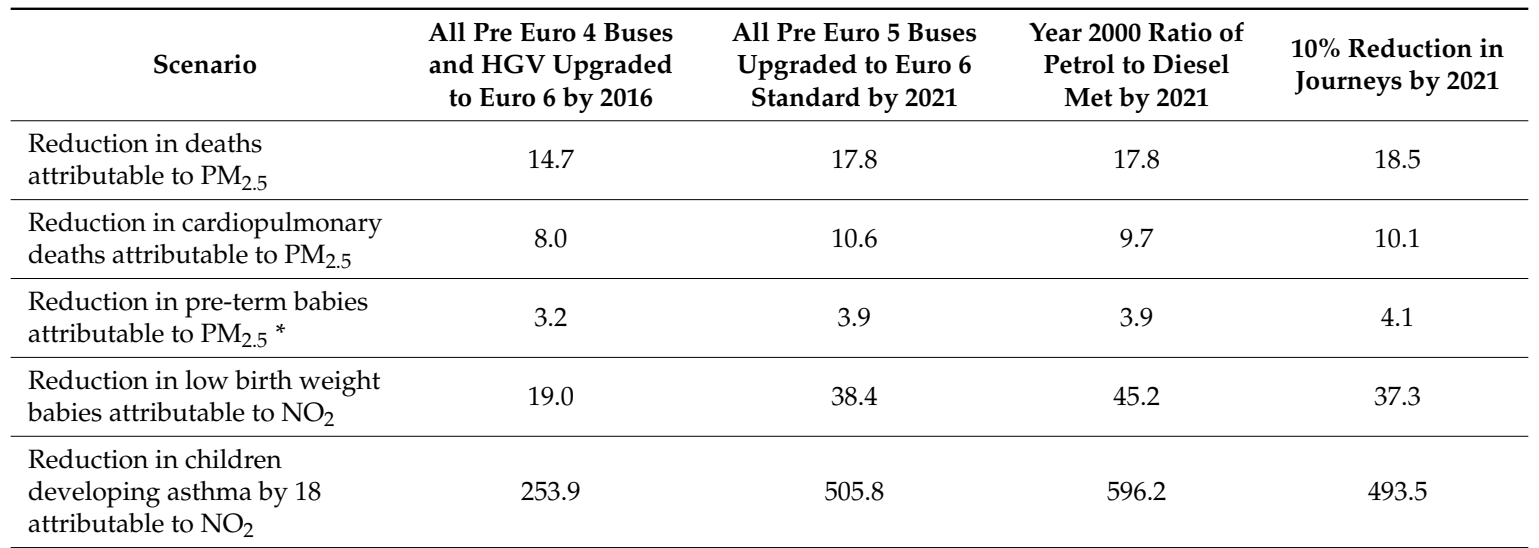

* The reduction in cardio-pulmonary deaths is not additional to the reduction in total mortality but is estimated from within a separate model so cannot be seen as a subset of the reduction in all deaths.

As it was possible to quantify the estimated reduction in deaths in each LSOA, mapping was undertaken and it was shown that the benefits of realising the above scenarios would extend to almost all of the study area. As deprived inner city areas and areas adjacent to major roads were the most likely to be affected by poor air quality and to suffer adverse health effects, these are the parts of Leeds and Bradford where low emission strategies could have the largest beneficial impact. The results of this HIA informed the LEZ feasibility study and overall emissions strategy development within the regional, and were used to successfully bid for further funding.

\subsection{Policy}

Following the LEZ feasibility modelling - and together with ongoing research outputs-a process of core policy development commenced, culminating in the publication of a number of regionally-endorsed policy documents.

\subsubsection{West Yorkshire Low Emissions Strategy}

The vision of the WYLES is to deliver cleaner air for all in West Yorkshire, and sets an ambitious 'wider determinants of health'-based agenda to create a low emissions future and contribute to healthier and more sustainable lives, as well as deal with immediate hazards to health of particulate matter and air pollution in general [5]. The strategy sets a framework for local partner activity and the divestment 
of local funding streams (e.g., public health grant, local growth deals, community infrastructure levies) through the oversight of the West Yorkshire Transport and Health Board.

The approach is systemic, recognising that economic, health, environmental and infrastructure issues all impinge on the achievement of lower regional emissions, and can all act as drivers for change. For example, economically, the four priorities of the Leeds City Region Strategic Economic Plan 2016-2036 [12] are mapped against air quality priorities for potential impact. Opportunities for economic and emissions synergies are noted, such as investment in Low Carbon and Environmental industries, higher paid jobs in clean vehicle technology, more resource efficient businesses, and development of low emission fuels and technology. Risks are also identified, such as increased biomass fuel risks, increased road capacity challenges, and localised power and heat generation causing localised air quality problems. In terms of energy generation, issues around new local heat and energy production are discussed, with links made to evolving energy sectors such as shale gas extraction and the significant growth of the renewable energy sector within the Leeds City Region Strategic Economic Plan.

The designation of parts of Leeds City Centre as a Clean Air Zone in December 2015, with restrictions placed on certain types of vehicle entry, is a key plank of this strategy, and is likely to be rolled out in further areas of the region.

\subsubsection{Draft West Yorkshire Transport Strategy}

The draft West Yorkshire Transport Strategy has a broad remit, aimed at improving the customer and traveler experience, growing the economy, and transforming local, northern and national connectivity within the transport network over the next 20 years [13]. At its heart is a travel modal shift model, made clear by a proposed set of targets to grow the number of journeys made by using sustainable transport by $25 \%$ more trips made by bus, $50 \%$ more trips made by rail and $100 \%$ more trips made by bicycle in the region by 2026. Policies included in the document thus take a resilience and sustainability approach, and include improving the road network, contributing to healthy places to live and work, creating 'One System' public transport, and a cross-cutting theme around the environment, health and wellbeing, and inclusion.

\subsubsection{West Yorkshire Air Quality and Emissions Technical Planning Guidance}

An Air Quality and Emissions Technical Planning Guide was developed as part of the WYLES to support the design and assessment of new developments to ensure that air quality is taken into account [15]. This includes a categorization framework for developments into minor, medium and major developments depending on their potential emission impact, with matched exposure assessment and mitigation measures for each category. Developments are designated on size of the development (e.g., $\mathrm{m}^{2}$ gross floor area) and are marked as 'major' if, for example, proposals create significantly higher traffic flow, increased congestion, heavy goods vehicle (HGV) movement, or are positioned within an air quality management area. Major proposals are required to calculate the damage costs (in air quality terms) using the government's Green Book Guidance [16], and are recommended to mitigate their impact including for example a comprehensive suite of compensatory measures included in the guidance.

With development decisions in each authority taken by their own planning officers and elected members, there is local determination in the implementation of the Technical Planning Guidance. However the guidance has been welcomed by planners and offers them a standard set of mitigations at planning application stage which can control potential emissions impacts, put in place through the use of planning conditions by each local authority or compensatory agreements such as section 106 levies.

\subsection{Bids}

A number of successful funding bids have supported the development of the WYLES. Central to this was the ability to use the data from local research to demonstrate the projected gains from specific interventions. The Clean Vehicle Technology Fund bid demonstrates this, using data from 
the LEZ study and HIA to quantify predicted health benefits of upgrading pre-Euro IV buses $[17,18]$. The grant and match funding enabled 25 buses to be upgraded to Euro V standard. Portable emissions measurement systems were employed to monitor emissions, and demonstrated a $95 \%$ reduction in NOx, equivalent to around 25 tonnes per year. This example shows a rapid turnaround from research into practice, made possible by the Department for Transport grant and local match funding.

\subsection{Recognition}

Bradford (as lead authority) has received a number of awards for the collaborative work; these include the Sustainable City Award (Air Quality), 2014 [19] and Fleet heroes' awards (2016) [20].

\section{Discussion}

This paper has provided an overview of the approach to air quality management taken to date in West Yorkshire. This approach stands out in terms of its wide engagement and broad successes, suggesting that improving air quality requires such collaboration and addressing complex factors.

\subsection{Health Impact Assessment}

We may have underestimated the true health benefits of these scenarios as population exposure models can underestimate personal exposure by up to 50\% [21], and we have not included changes in other potentially harmful pollutants such as ozone or quantified the health impact of short term 'spikes' in NOx and $\mathrm{PM}_{2.5}$. In addition, we have only modelled health effects where quantifiable estimates based on meta-analysis are available. Evidence is emerging for other health effects of air pollution (e.g., diabetes [22] or traffic noise [23]).

The LEZ scenarios are presented as independent of each other, whereas in combination they represent a multifaceted approach to reducing road emissions. Additive benefits would be seen, for example, by combining improvements to bus and LGV engines with policies that encourage greater use of hybrid engines, reduced congestion and more active travel such as cycling and walking.

\subsection{Other Research Outputs}

A number of other key research outputs emerged from the collaboration, demonstrating an iterative process of policy and research development. Economic analysis from the University York Centre of Health Economics used modelling that is more typically applied to health interventions than air quality research to enable comparison of costs and benefits with other health interventions [24]. The research used one intervention (reducing emissions from buses and heavy goods vehicles from 2012 levels to the Euro 6 standard by 2016) and modelled the impact on all-cause mortality and low birthweight in term babies; and prevalence of childhood asthma and their cost to the NHS and personal social services. This research demonstrated that when comparing the cost of upgrading the fleet with the savings from improved health, the intervention would be cost effective in less than eighteen months. However, it is key to note that is based on money saved through reduced healthcare usage, which accrues to the NHS rather than other partners. This fed in to discussions around low emissions zones and has thus had direct impact. This work also led to the development of a national toolkit which local authorities can now use to assess the potential benefits in their localities.

The HELIX project (part of the European Study of Cohorts for Air Pollution Effects (ESCAPE) project) used cohort data from twelve European countries to demonstrate that exposure to particulate matter and traffic density on the nearest street are both associated with restricted fetal growth [11]. The research was driven by Born in Bradford, a local cohort study of more than 12,000 children and families followed from birth, and City of Bradford Metropolitan District Council provided support through membership of the steering group.

Research was developed as part of the strategy development to seek a greater understanding of the choices made by parents in terms of school travel. Research by Ahern et al. explored parents' school 
travel choices in urban areas of West Yorkshire and concluded that the two factors most likely to be barriers to active travel to school were distance from home to school and being a working parent [25].

\subsection{Benefits of Joint Working}

There have been considerable benefits from the collaborative approach described. Firstly, the approach allowed local authorities to better align their work with health priorities, by including priorities in the Joint Strategic Needs Assessments and Director of Public Health reports, and by engaging Health and Wellbeing boards and Sustainability and Transformation Plans. The partnerships that stakeholders developed led to wider networks and broader collaborations which can be used to engage on other issues in the future. Improved understanding across organisations ensures that people appreciate that health benefits that may initially accrue to healthcare partners will 'filter through' in the long term to other partners, for example through creating a stronger workforce, more economic activity, meeting objectives in the Strategic Economic Plan and increasing climate resilience of the region as a whole.

The process of the strategy development contributed to an increased awareness of air quality as a priority policy area. For example, the level of seniority at meetings changed throughout the process, from predominantly specialist officers at the outset to far more senior decision-makers as time went on. The breadth of involvement also widened, with increased engagement from related disciplines for example planning and fleet management, this can be seen in the engagement of planners seeking regional consistency on air quality issues, who have embraced the development of the West Yorkshire Air Quality and Technical Planning Guidance.

\subsection{Challenges of Joint Working}

There are of course challenges with joint working, particularly when involving a number of different organisations where there can be varying levels of engagement from stakeholders and different ways of working. In addition, the way funding is distributed can sometimes lead to problems due to competition, though this can be addressed collaboratively by sharing ideas or through joint bidding. Openness and honesty and a recognition of potential conflicting interests when they arise has been important during the strategy development and will continue to be so during implementation. Achieving sign off for the strategy from all the different organisations involved took a considerable amount of time which may have reduced the momentum built up during the development process. A balance has to be struck between radical and forward thinking ideas, and the need for all partner organisations to be able to sign up to the strategy. Being cognisant of the political climate at all levels was a requirement for the strategy's development and adoption.

Since UK air quality regulations are derived from European Union (EU) regulations, Brexit will mean that enforcement of air quality regulations will be handled differently once the UK leaves the EU. So far, this has not translated into a reduction in focus on air quality improvement, in fact the UK government has indicated renewed emphasis for this area of work and is now requiring action for air pollution to be reduced below legal limits through a national Clean Air Zone framework and new Air Quality Plan [26] for the UK. However, it is unclear at time of publication the precise legal framework for air quality in the UK in the coming years.

\subsection{Key Lessons}

There are a number of key lessons for other areas wishing to take a similar approach. Firstly, it is hard to understate the importance of multidisciplinary engagement. Developing and continuing this collaboration required enthusiasm to engage stakeholders and develop projects; at times this can involve opportunistic pitching of ideas at events to draw in collaborators, but it also involves identifying and understanding stakeholders' priorities and finding ways that air quality can be incorporated with those. Sharing work is crucial to getting other people involved, and in particular publications and awards lead to greater recognition and help build momentum around initiatives. 
To ensure collaborations remained focused, distinct projects can be of benefit and persistence is needed to keep the issues on the agenda. Offering support to stakeholders can ensure that work does not slip. Where possible, having staff jointly appointed by partner organisations can help progress collaborations.

To sustain this engagement, advocates should not just emphasise the direct health impacts that poor air quality causes but the opportunities and benefits that can arise from improving it. For example, a modal shift to public transport provides an opportunity to increase active travel, with an emerging evidence-base that this may reduce diabetes and obesity, and improve cardiovascular and respiratory health as well as aiding mental wellbeing $[27,28]$. Planning developments around pedestrians and cycling can reduce car use, increase active travel, reduce congestion, improve air quality and may make places more pleasant to live in and encourage new business to invest; recent guidance on the effectiveness of interventions in this field has recently been issued by the UK National Institute for Health and Care Excellence (NICE). [29]. Broadening the agenda beyond just air quality to include these wider determinants of health appeals to more stakeholders (including elected members) encourages wider engagement and provides more opportunities and levers to influence strategy and policy.

Demonstrating impacts is also necessary to maintain enthusiasm. For example, in our case the WYLES Board successfully connected the outputs of local research with bids to bring in money for new projects, thus driving a cycle of change in the local area and bringing stakeholders along by showing them that change is possible through joint working.

\subsection{Critical Reflection}

Progress to date has been largely transport and planning focused-indeed these may represent the quick wins, which are vital to ensuring the long term sustainability of the strategy. Areas for future development include home heating and work around energy supply. The complex nature of air pollution provides an opportunity for multidisciplinary engagement and wide ranging interventions; not just from one sector. Further development will also need to ensure ownership of the WYLES beyond local authorities to involve private organisations and other parts of the public sector. The extent to which measureable improvements in health and local air quality have occurred is also still to be demonstrated (as the implementation of the strategy has just started at time of press).

\subsection{Link with Evidence Base}

We would like to highlight several key links with the literature. Firstly, the complexity of factors involved in air quality supports its conceptualization as a wicked problem [30]. These types of problems are often multifactorial and hard to address, and collaborations are one of the key approaches to tackling them, in particular working across organisations and in new ways.

Secondly, the process of policy development we have described can be understood using transitions management theory [31]. This multidisciplinary complexity science based approach has derived from empirical studies of large scale shifts in society such as case studies of changes in agriculture or energy supply. The approach offers methods for policy change which include the development of transition arenas-spaces and platforms where new policies can be developed using stakeholders, niche projects can be identified and greater societal change occurs when these niches coalesce. We would thus argue that building collaborative policy and developing small scale local projects has allowed us to build into a broader movement, supporting the integration of our projects and slowly changing the landscape around us.

Thirdly, the process in West Yorkshire can be understood as a multiscale and interacting open system [32]. There are clear links between work at a local level which has resulted in specific local initiatives, work at a regional level which has allowed the broader strategy, and other related strands of work such as the development of a West Yorkshire Transport Strategy. This again reinforces the importance of collaboration with key stakeholders acting as bridges between different scales and work streams. 
Finally, the experience in California has shown that strong policy can help reduce air pollution and thus deliver health benefits [33]. We provide direct insight into the process that has been used to develop local evidence, develop associated policy and generate broad engagement with the issue of air pollution. This paper will thus interest advocates and stakeholders who are facing similar challenges.

\subsection{Strengths and Limitations}

This paper provides a comprehensive overview of the local approach taken locally, using supporting evidence from peer reviewed publications and other presentations. As no primary research has been carried out for this paper it is not possible to explore in detail the factors relating to this initiative; and further research is needed to fully understand the potential benefits and limitations of such an approach. It must also be highlighted that this approach may not be directly replicable elsewhere as some achievements may depend on local factors, though the benefits of multi-sector and collaborative working are evidently generalisable. We would also highlight the complex, dynamic and scalar nature of work on this topic, which limits the potential to provide a comprehensive and detailed overview of all aspects of the policy development process. We also do not evaluate the potential for health co-benefits alongside WYLES; this should form part of future work.

\section{Conclusions}

Air pollution is a complex problem that is being tackled in West Yorkshire through a collaborative approach. This is consistent with the conceptualization of air quality as a wicked problem and latest theories of broad societal change. Policy makers should ensure they involve a broad range of stakeholders on specific projects, by continually raising the profile of air quality and by ensuring that tangible impacts are realized within reasonable timescales to build on success. More research is required to evaluate the actual impact of local initiatives on air pollution levels and any associated health benefits.

Acknowledgments: A range of funding was available for stages of this project. The majority of funding has come from the Department for Environment, Food and Rural Affairs (DEFRA); the National Institute for Health Research's Collaborations for Leadership in Applied Health Research programme (CLARCH); and the West Yorkshire Combined Authority (WYCA). Full details of funding are available on request. No special funding was available for this article or its publication.

Author Contributions: Yannish Naik and Sally Jones conceived the paper. Duncan Cooper carried out the Health Impact Assessment of Low Emissions Zones. All authors contributed substantially to the content of the paper.

Conflicts of Interest: The authors declare no conflict of interest. The founding sponsors had no role in the collection, analyses, or interpretation of data; in the writing of the manuscript, and in the decision to publish the article.

\section{References}

1. Royal College of Physicians. Every Breath We Take: The Lifelong Impact of Air Pollution. Report of a Working Party. 2016. Available online: https:/ / www.rcplondon.ac.uk/projects/outputsevery-breath-wetake-lifelong-impact-air-pollution (accessed on 30 May 2017).

2. European Parliament. Directive 2008/50/EC of the European Parliament and of the Council of 21 May 2008 on Ambient Air Quality and Cleaner Air for Europe. 2008. Available online: http:/ / eur-lex.europa.eu/legalcontent/EN/ALL/? uri=CELEX:32008L0050 (accessed on 30 May 2017).

3. ONS. Population Estimates for UK, England and Wales, Scotland and Northern Ireland: Mid-2016. Available online: https:/ / www.ons.gov.uk/peoplepopulationandcommunity/populationandmigration/ populationestimates/bulletins/annualmidyearpopulationestimates/latest (accessed on 30 May 2017).

4. Cooper, D.; Crowther, R.; Dixon, R.; Jones, S.; Gent, M. A feasibility study to assess population exposure and health effects of road pollutants in Leeds and Bradford. PHE Poster 2014. Unpublished.

5. City of Bradford MDC; Calderdale Council; Kirklees Council; Leeds City Council; Wakefield Council; West Yorkshire Combined Authority. West Yorkshire Low Emissions Strategy, 2016-2021. 2016. Available online: https: / / www.bradford.gov.uk/media/3590/west-yorkshire-low-emissions-strategy.pdf (accessed on 30 May 2017). 
6. Crowther, R. Initial findings from the LEZ source apportionment work for Leeds and Bradford. Unpublished, 2003.

7. COMEAP. Long-Term Exposure to Air Pollution: Effect on Mortality. A Report by the Committee on the Medical Effects of Air Pollutants. 2009. Available online: http://www.comeap.org.uk/documents/ reports/39-page/linking/51-the-mortality-effects-of-long-term-exposure-to-particulate-air-pollution-inthe-united-kingdom (accessed on 7 March 2014).

8. COMEAP. The Mortality Effects of Long-Term Exposure to Particulate Air Pollution in the United Kingdom: A Report by the Committee on the Medical Effects of Air Pollutants. 2010. Available online: http://www.comeap.org.uk/documents/reports/39-page/linking/51-the-mortality-effects-oflong-term-exposure-to-particulate-air-pollution-in-the-united-kingdom (accessed on 7 March 2014).

9. Cesaroni, G.; Forastiere, F.; Stafoggia, M.; Andersen, Z.J.; Badaloni, C.; Beelen, R.; Caracciolo, B.; de Faire, U.; Erbel, R.; Eriksen, K.T.; et al. Long term exposure to ambient air pollution and incidence of acute coronary events: Prospective cohort study and meta-analysis in 11 European cohorts from the ESCAPE Project. BMJ 2014, 348, f7412. [CrossRef] [PubMed]

10. Pedersen, M.; Giorgis-Allem, L.; Bernard, C.; Aguilera, I.; Andersen, A.-M.N.; Ballester, F.; Beelen, R.M.J.; Chatzi, L.; Cirach, M.; Danileviciute, A.; et al. Ambient air pollution and low birthweight: A European cohort study (ESCAPE). Lancet Respir. Med. 2013, 1, 695-704. [CrossRef]

11. Takenoue, Y.; Kaneko, T.; Miyamae, T.; Mori, M.; Yokota, S. Influence of outdoor $\mathrm{NO}_{2}$ exposure on asthma in childhood: Meta-analysis. Pediatr. Int. 2012, 54, 762-769. [CrossRef] [PubMed]

12. LCREP and WYCA. Leeds City Region Strategic Economic Plan 2016-2036. 2016. Available online: http:/ / www. the-lep.com/LEP/media/New/SEP\%20documents/SEP-2016-2036-FINAL.pdf (accessed on 9 May 2017).

13. West Yorkshire Combined Authority; City of Bradford MDC; Calderdale Council; Kirklees Council; Leeds City Council; Wakefield Council. West Yorkshire Transport Strategy 2016-2036 Full Consultation Draft. 2016. Available online: http:/ /www.westyorks-ca.gov.uk/uploadedFiles/Content/Transport/Transport_Plan/ Transport-strategy-full.pdf (accessed on 9 May 2017).

14. 38 Degrees. Clean Our Air It's Killing Us. 2016. Available online: https://you.38degrees.org.uk/petitions / clean-our-air-it-s-killing-us-1 (accessed on 30 May 2017).

15. City of Bradford MDC; Calderdale Council; Kirklees Council; Leeds City Council; Wakefield Council. Air Quality \& Emissions Technical Planning Guidance. 2016. Available online: https:/ / www.bradford.gov.uk/ media/3591/air-quality-and-emissions-planning-guide.pdf (accessed on 22 May 2017).

16. Dickens, R.; Gill, J.; Rubin, A.; Butterick, M. Valuing Impacts on Air Quality: Supplementary Green Book Guidance DEFRA. 2013. Available online: https://www.gov.uk/government/publications/green-booksupplementary-guidance-air-quality (accessed on 30 May 2017).

17. Jones, T. Clean Vehicle Technology Fund. Powerpoint presentation supplied to Sally Jones. Unpublished.

18. Coach and Bus Week 06/10/14. Mybus Goes Green. Available online: https://cbwmagazine.com/mybusgoes-green/ (accessed on 22 May 2017).

19. Telegraph and Argus. Bradford Council Scoops Clear Air Award. 2014. Available online: http:/ / www.thetelegraphandargus.co.uk/news/newsindex/11115475.Bradford_Council_scoops_clear_air_ award/?ref=arc (accessed on 22 May 2017).

20. Energy Saving Trust. 2016 Winners. Available online: http:/ /www.fleetheroawards.org.uk/2016-winners (accessed on 30 May 2017).

21. Kioumourtzoglou, M.; Spiegelman, D.; Szpiro, A.; Sheppard, L.; Kaufman, J.; Yanosky, J.; Williams, R.; Laden, F.; Hong, B.; Suh, H. Exposure measurement error in $\mathrm{PM}_{2.5}$ health effects studies: A pooled analysis of eight personal exposure validation studies. Environ. Health 2013, 13, 2. [CrossRef] [PubMed]

22. Rajagopalan, S.; Brook, R.D. Air Pollution and Type 2 Diabetes: Mechanistic Insights. Diabetes 2012, 61, 3037-3045. [CrossRef] [PubMed]

23. Nrepepa, A.; Twaedella, D. Relationship between noise annoyance from road traffic noise and cardiovascular diseases: A meta-analysis. Noise Health 2011, 13, 251-259. [CrossRef]

24. Lomas, J.; Schmitt, L.; Jones, S.; McGeorge, M.; Bates, E.; Holland, M.; Cooper, D.; Crowther, R.; Ashmore, M.; Rojas-Rueda, D.; et al. A pharmacoeconomic approach to assessing the costs and benefits of air quality interventions that improve health: A case study. BMJ Open 2016, 6, e010686. [CrossRef] [PubMed] 
25. Ahern, S.; Arnott, B.; Chatterton, T.; de Nazelle, A.; Kellar, I.; McEachan, R. Understanding parents' school travel choices: A qualitative study using the Theoretical Domains Framework. J. Transp. Health 2017, 4, 278-293. [CrossRef]

26. DEFRA. Improving Air Quality: Reducing Nitrogen Dioxide in Our Towns and Cities: A Consultation Plan. 2017. Available online: https:/ / www.gov.uk/government/consultations/improving-air-quality-reducingnitrogen-dioxide-in-our-towns-and-cities (accessed on 22 May 2017).

27. Saunders, L.E.; Green, J.M.; Petticrew, M.P.; Steinbach, R.; Roberts, H. What Are the Health Benefits of Active Travel? A Systematic Review of Trials and Cohort Studies. PLoS ONE. 2013, 8, e69912. [CrossRef] [PubMed]

28. De Nazelle, A.; Nieuwenhuijsen, M.J.; Antó, J.M.; Brauer, M.; Briggs, D.; Braun-Fahrlander, C.; Cavill, N.; Cooper, A.R.; Desqueyroux, H.; Fruin, S.; et al. Improving health through policies that promote active travel: A review of evidence to support integrated health impact assessment. Environ. Int. 2011, 37, 766-777. [CrossRef] [PubMed]

29. NICE (2017) Air Pollution: Outdoor Air Quality and Health. Guidance NG70. Available online: https: / / www.nice.org.uk/guidance/ng70 (accessed on 31 July 2017).

30. APSC. Tackling Wicked Problems: A Public Policy Perspective. 2012. Available online: http:/ /www.apsc. gov.au/publications-and-media/archive/publications-archive/tackling-wicked-problems (accessed on 30 May 2017).

31. Grin, J.; Rotmans, J.; Schot, J. Transitions to Sustainable Development: New Directions in the Study of Long Term Transformative Change; Routledge: London, UK, 2010.

32. Chu, D.; Strand, R.; Fjelland, R. Theories of Complexity. Complex 2003, 8, 19-30. [CrossRef]

33. Gauderman, W.J.; Urman, R.; Avol, E.; Berhane, K.; McConnell, R.; Rappaport, E.; Chang, R.; Lurmann, F.; Gilliland, F. Association of Improved Air Quality with Lung Development in Children. N. Engl. J. Med. 2015, 372, 905-913. [CrossRef] [PubMed]

(C) 2017 by the authors. Licensee MDPI, Basel, Switzerland. This article is an open access article distributed under the terms and conditions of the Creative Commons Attribution (CC BY) license (http:/ / creativecommons.org/licenses/by/4.0/). 